\title{
Online Career Guidance System
}

\author{
Saad Ahmed, Suraj Prakash Maurya, Vaibhav Khalane \\ B.E. Student, Department of Computer Engineering, \\ Met's Institute of Engineering, Nashik, India
}

\begin{abstract}
In today's competitive world the selection of right career path or academics is a big challenge. Educational and Career Guidance is not as simple task as it sounds and it is a complicated thing, which depends upon many factors and aspects. Nowadays Career counselors are available to help students in selecting streams in education or to provide guidance regarding career selection. They are rarely available in rural areas. Unfortunately, some of them are biased due to their personal experiences and opinions, hence are not able to provide right suggestions to the students. Most of the counsellors charge high fees hence they are not accessible to each and every individual. We need a reliable, unbiased and effective system which can reduce this issue and will able to neutralize the complexity of such problems. Our application CGS (Career Guidance System) is an approach to resolve such problems and provide a better guidance to the students for building their academics and have a clear career perspective helping them to achieve the zenith of the success in the life. This small application can make a big difference if it is used and followed in a structured manner.
\end{abstract}

Key Words: Career, Guidance, Career Guidance, Online Career Guidance, Education, Educational

\section{INTRODUCTION}

Choosing a career is not always an easy task for students, especially since the choice should be based on several criteria and at a relatively early age. This important decision not only affects the academic and professional life of the student but also the efficiency of schools [1]. In fact, a bad educational or professional guidance may be at the origin of several educational and social problems: school failure, school dropout, lack of skills, integration difficulties, unemployment, etc.
Career development is a lifelong process. There are a number of factors that influence your career development, including your interests, abilities, values, personality, background, and circumstances. Career Guidance [2] is a process that will help you to know and understand yourself and the world of work in order to make career, educational, and life decisions. Career Guidance can be referred to as a service provided by the particular school to help students in making clever decision and changes so as to develop their potentials as an individual and a contributing member of the society. It is a process of helping a person to realize and grow his/her vocational, educational, and psychological potentials and also achieving the best level of individual happiness and societal usefulness. Career guidance consists of services that help people successfully manage their career planning and development [3].

The internet has become a place where students(youth) visit often to interact, shop, be entertained etc. Internet should also be used for something as productive and as important as interacting with an information system that helps them to choose the best career possible for them [5]. The proposed system is a Online Career Guidance System which will address the concerned problems. The proposed system will evaluate students on various aspects to suggest a career path. This aspect are personal interests, personality traits, skills, aptitude, comfort, etc. This system will remove problem of lack of fast and reliable access to useful information needed to make career choices. If this system is used in a constructive manner, an online career counselor can be more effective and accessible than a real life counselor. It can be used to complement real life counselors; it can serve as a tool used by them. 


\section{Existing System}

The existing systems has many drawbacks such as career counselors are not available always as per the individual's comfort. Guidance and counseling has been limited to few institutions therefore not all the students can get counselling. Counselors and career guidance websites charge huge fees for guidance which is not affordable for large group of society. Many websites have clumsy GUI and users find it difficult to use.

Sometimes counselors may not be committed and can sometimes be unapproachable.

The problem of Generation gap. Students may find uncomfortable to approach a guide who is older in age.

\section{Proposed System}

The proposed system consists of various modules as shown in figure 1.

Login: User will be provided with the welcome GUI. The user will log in accordingly.

Registration: When the user logs in for the first time, he/she would be required to fill in the registration details. If the user doesn't have credentials to $\log$ in the system, it is but obvious that he/she would first require registering themselves in the system.

Question Addition: Using this module, admin can add and remove questions in the database.

Test Paper Preparation: In this module, admin can select the desired questions from the question database for the test.

Exam Conduction/Result: Tests conduction will be done using this module. Students will appear for test in this module.

Result Analysis: Results of all the tests will be analyzed to generate a final result.

Report Generation: Report will be generated considering final result. Suggestions will be given to students in this module.

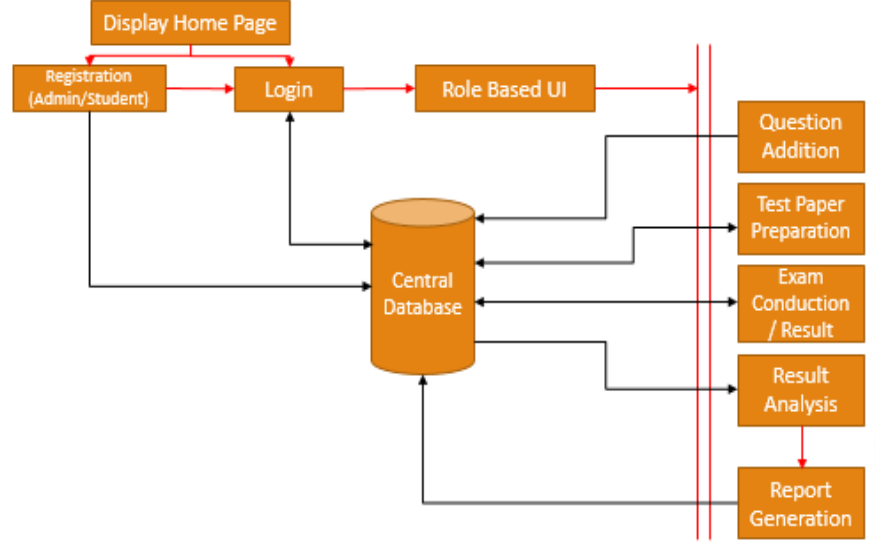

Fig.1 Architecture of Proposed System

\section{Test Details}

To evaluate students, tests will be conducted to understand personality traits, aptitude, interests. The tests will be General Aptitude test, Personal Interest test, Domain test and Personality test [6].

General Aptitude Test - Every career option requires a particular aptitude combination that should match with the individual's potential ability to grow with that career. Aptitude is basically defined as an innate, learned or acquired ability of an individual to perform certain tasks. Aptitude tests [4] inculcate many factors like Numerical reasoning, verbal reasoning, abstract reasoning, speed, accuracy and other such abilities.

Personal Interest Test - Interests can tell you more on who you are and what suits you. They provide information necessary for making the right career choice. Obviously, interests indicate what one likes and what occupations interest them. If the profession one choose connects with these interests, they will find a lot more pleasure in their work.

Domain Test [5] - Domain test helps analyze student's performance in different domains such as English, Math, Reading, Science.

Personality Test - The term personality typically refers to one's characteristic pattern of thinking, feeling, and behaving. A growing body of research has shown important connections between personality constructs and a broad array of career behaviors including individuals' approach to learning, vocational interests, career choices, self-esteem, confidence in performing tasks, career counseling interactions, job searches, and subsequent work performance, satisfaction, and tenure [6]. 
The combined result of these tests will be used to suggest career path to student.

\section{Use Case Diagram}

Use case diagram is as stated in figure 2. Student will have to register on the platform to get access to further functionalities. Student will be asked to fill a form which collects basic details of student.

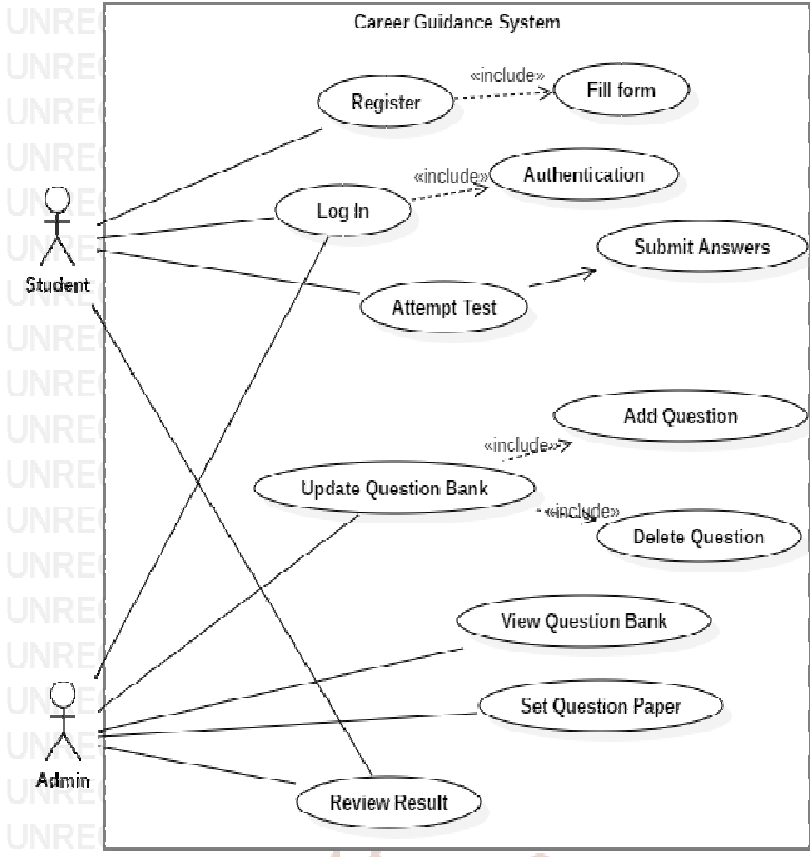

Fig. 2 Use Case Diagram components locally, a developer can build and test a dynamic website before publishing it to a public web server.

\section{Technology:}

HTML 5: Hypertext Markup Language (HTML) is the standard markup language for creating web pages and web applications. It is the most widely used language on Web to develop web pages.

CSS: CSS is a language that describes the style of an HTML document. CSS describes how HTML elements should be displayed.

JavaScript: JavaScript is used to program the behavior of web pages. JavaScript is a lightweight, interpreted programming language. Alongside HTML and CSS, JavaScript is one of the three core technologies of the World Wide Web.

PHP 5.2.0: PHP (Hypertext Preprocessor) is a serverside scripting language designed for Web development, and also used as a general purpose programming language. PHP can be embedded into HTML.

MySQL: MySQL is an open source relational database management system based on Structured Query Language (SQL). With PHP, databases can be connected and manipulated.

Student and admin will have to login in order get access of the system. Student will be able to attempt tests and review result. Admin will be able to update question bank, add or delete questions, view question bank, set question paper and review result.

\section{Technologies to be used}

Hardware and software requirements for the system are stated below

\section{Software:}

WAMP Server: Stands for "Windows, Apache, MySQL, and PHP." WAMP is a variation of LAMP for Windows systems and is often installed as a software bundle (Apache, MySQL, and PHP). It is used for web development and internal testing, but may also be used to serve live websites. WAMP package includes Apache (or "Apache HTTP Server") web server within Windows. WAMP also includes MySQL and PHP, which are two of the most common technologies used for creating dynamic websites. MySQL is a high-speed database, while PHP is a scripting language that can be used to access data from the database. By installing these two

\section{Operating System: Windows 7 and above}

Hardware: Intel Pentium 4 Processor and above, 1 GB RAM Minimum, 150 GB Hard Disk Minimum

\section{Conclusion}

Student's bright future is the crucial for development of the country. This is why in this paper we have tried to present a model for guiding the student to their best appropriate pathway, so they can excel in their professional career. The opportunities provided by the technology are immense and many students can make use of this platform to choose a career more appropriate to their skills. Various challenges in manual career guidance system has been recognized to design effective online career guidance system. Implementing this system will help young ones to choose right career path that best suits them. This application will fulfill the need of fast and reliable access to information that is needed to make right career choice. 
It can also serve as a complimentary tool for career guides and counselors. This application will suggest various career choices, job opportunities for such careers and associated benefits; making the student architect of their own career.

\section{References}

1. Abisoye Opeyemi "A Web Based Career Guidance Information System for Pre-Tertiary Institution Students in Nigeria", In Federal University of Technology, Department of Computer Science, Minna, Niger State, Nigeria, June 2015.

2. Crystal D'Mello "Online Career Guidance System", In International Journal of Advanced Research in Computer Science and Software Engineering, April 2016.
3. S. Saraswathi, M. Hemanth Kumar Reddy, S. Udaya Kumar, M. Suraj, Sk. Khaja Shafi "Design of an online expert system for career guidance", IJRET: International Journal of Research in Engineering and Technology Pondicherry, India, May 2014.

4. A. J. Metz, Janice E. Jones "Ability and Aptitude Assessment in Career Counseling", https://www.researchgate.net/publication/2820494 90

5. http://blog.careerfutura.com/dedicated-onlineportals-offering-career-counseling-forprofessionals-seeking-change-of-stream/

6. Claudia Crisan, Anis oara Paveleab, Oana Ghimbulut, "A Need Assessment on Students Career Guidance" BProcedia - Social and Behavioral Sciences 180201510221029 